\title{
Rate of Couple HIV Testing in a Prenatal Care Clinic and Factors Associated with Refusal of Testing Among Male Partners
}

\author{
Achara Pollahan (1D' \\ Jadsada Thinkhamrop (D) \\ Kiattisak Kongwattanakul (D) \\ Sukanya Chaiyarach' \\ Nutwara Sutthasri (iD) ${ }^{2}$ \\ Kesorn Lao-unka ${ }^{2}$ \\ 'Department of Obstetrics and \\ Gynaecology, Faculty of Medicine, Khon \\ Kaen University, Khon Kaen 40002, \\ Thailand; ${ }^{2}$ Nursing Department, \\ Srinagarind Hospital, Faculty of Medicine, \\ Khon Kaen University, Khon Kaen 40002, \\ Thailand
}

This article was published in the following Dove Press journal: HIVIAIDS - Research and Palliative Care

\begin{abstract}
Objective: To determine the rate of HIV testing in couples during pregnancy and the reasons and risk factors related to male partners refusing to be tested.

Materials and methods: This was a cross-sectional study conducted in pregnant women undergoing prenatal care after receiving information about HIV testing on their first visit. After 20 weeks of gestation, they were approached to participate in the study, which consisted of an interview and examination of their medical records. Data collection included the women's socioeconomic status, obstetric condition and serological test results together with their partner
\end{abstract} information. If relevant, the partner's reasons for refusing to undergo HIV testing.

Results: A total of 400 pregnant women were recruited between February and August 2018, $150(37.5 \%)$ of whose male partners underwent HIV testing. There were five couples in which one or both members were found to be positive for HIV: 1 seroconcordant couple, 1 serodiscordant couple in which the pregnant woman was positive, and 3 serodiscordant couples in which the male partners were positive. The most common reason for male partners refusing to take the test was their already having been tested once before. The women having had other sexual partners prior to their current partners was a significant risk factor for the partners refusing to be tested.

Conclusion: There was a low rate of couple HIV testing and a substantial portion of discordant infection among positive couples. Routine couples counseling and testing should be encouraged to reduce the vertical transmission and the number of new cases of HIV infection.

Keywords: couples HIV testing and counseling, prevention of mother-to-child-transmission, risk factors, pregnancy

\section{Introduction}

According to the 2018 global HIV and AIDS statistics fact sheet produced by UNAIDS, there are around 36.9 million living with HIV, and approximately $80 \%$ of the pregnant women living with HIV are able to access to antiretroviral medicines to prevent transmission of HIV to their infants. There has been a worldwide decrease in new HIV infections from 3.4 million in 1996 to 1.8 million in 2017, and mortality from AIDS-related illness has dropped from 1.9 million in 2004 and 1.4 million in 2010 to less than 1 million $(940,000)$ in $2017 .{ }^{1,2}$

According to the AIDS epidemic model for adults and spectrum for children, at the end of 2014 in Thailand, there were estimated 7816 new HIV infections, 20,492 AIDS-related deaths, and 445,504 persons living with HIV. $^{3}$ The rate of new HIV
Correspondence: Jadsada Thinkhamrop Department of Obstetrics and Gynaecology, Faculty of Medicine, Khon Kaen University, Khon Kaen 40002,

Thailand

Email jadsada@kku.ac.th 
infections among children has been dropping in Thailand. The estimated mother-to-child-transmission (MTCT) has dropped from $2.1 \%$ in 2014 to less than $2 \%$ in 2016 , meaning that Thailand could be one of the middleincome countries to eliminate MTCT. Furthermore, Thailand has set a goal to reduce the MTCT rate to below $1 \%$ by 2020 and has committed itself to ending the AIDS epidemic by 2030, which would mean there being no newborn infants with perinatal HIV. ${ }^{3}$

The main factors related to HIV infection during pregnancy are: 1) late ANC attendance among HIV-infected pregnant women, 2) poor medication compliance among some HIV-infected pregnant women, 3) late detection and treatment, and 4) breastfeeding with positive HIV status according to expedited HIV testing performed during labor or shortly after birth, which accounts for more than $10 \%$ of the perinatal HIV transmission cases. ${ }^{2}$ However, promoting couple HIV testing is also an important strategy in the prevention of mother-to-child transmission according to studies in Thailand have reported high (30-50\%) serodiscordant rates among HIV-infected couples. ${ }^{4}$ Another study in 2012 found that around 32\% of new HIV infections were among low-risk cohabitating couples, e.g., husband to wife or wife to husband. ${ }^{5}$ Another study found that $0.05 \%$ of the pregnant women had HIV seroconversion during pregnancy, presumably from their HIV-positive partners. ${ }^{6}$ One report found that in $2015,42 \%$ of the couples had undergone HIV testing during pregnancy or postpartum in Thailand. It also reported that $0.2 \%$ of the couples were HIV discordant (male+/female-) and predicted that the rate of HIV discordance would increase to 1500 persons per year. ${ }^{2}$

In 2012, the World Health Organization (WHO) recommended that couples should be offered voluntary counseling and testing (VCT) with support for mutual disclosure during antenatal care attendance. ${ }^{7,8}$ Offering couples HIV testing and counseling (CHTC) in ANC settings might also provide other benefits, for instance increasing male participation in ANC services, enhancing communication between couples about safe sex practices, 9,10 encouraging men to get tested and to know their HIV status, and preventing new HIV infections. ${ }^{7}$ In Thailand, $98 \%$ of the pregnant women receive ANC at health facilities, and most undergo routine HIV testing. ${ }^{11}$ In most ANC settings in Thailand, VCT is provided to men when their pregnant partners are HIV positive. ${ }^{4}$ In this context, the vertical transmission could not reduce especially when the couples had sero-discordant. Strategies that have been used in health facilities in Thailand and other countries to increase male contribution include making ANC services more male friendly (e.g., providing comfortable waiting space or fast-track registration for men) and providing health education to change their beliefs and attitudes. ${ }^{12}$ Other than that, CHTC has also been integrated into other maternal and child health programs such as thalassemia screening, syphilis screening, and parenting classes. ${ }^{13}$

The National Health Security Office (NHSO), an organization for universal health coverage development of Thai government, has created a policy to subsidize the cost of twice-per-year HIV testing, allowing couples to undergo routine testing at no charge. Despite this and many modalities to encourage to take the test, a substantial portion of couples still fails to get tested as mentioned above. We, thus, decided to examine the rate of couple HIV testing at ANC clinic in a tertiary care center (Srinagarind Hospital), as well as the reasons and factors related to male partners refusing to undergo HIV testing. The results of this study will provide useful information that can be applied to improve our services and lower the vertical transmission rate of HIV to as close to zero as possible in the near future.

\section{Materials and Methods}

This was a cross-sectional study conducted among pregnant women who received prenatal care at Khon Kaen University's Srinagarind Hospital in Khon Kaen, Thailand. We recruited 400 couples based on the evidence from the Thailand AIDs response progress report, which found that in $2014,41 \%$ of the couples receiving antenatal care underwent testing for $\mathrm{HIV}^{3}$ This allowed for a precision error of estimation of 5\%. This research protocol has been approved by the Khon Kaen University Ethics Committee in Human Research (HE601448).

Pregnant women who attend the antenatal care clinic on the first visit at Srinagarind Hospital receive information about HIV testing and brochures containing AIDs-related information and information regarding the importance of HIV testing. They then undergo HIV testing together with other routine screening blood tests including those for complete blood count (CBC), syphilis infection, Hepatitis $\mathrm{B}$ infection, and thalassemia (in cases in which red blood cell mean corpuscular volume (MCV) is $<80 \mathrm{fl}$. of $\mathrm{CBC}$ result). The women are asked to have their partners undergo blood testing for HIV, as well, either at the same time if their partners are present or on their next visit. HIV testing would be offered to all couples, though they have taken the test before with negative results but it was taken before the current pregnancy. On the other hand if they have had the 
test before with positive results they would be attained in another special clinic and be excluded from the study.

The women were approached to participate in the study after 20 weeks of gestation. After written informed consent was obtained, they were interviewed and their medical records were examined. Interviews were conducted to ascertain data regarding patients' baseline characteristics (age, marital status, duration of their relationship with their current partner, education, occupation, average income, contraceptives used, history of previous abortion, gestational age at initiation of $\mathrm{ANC}$, pretest and posttest counseling, and history of sexually transmitted infection), information regarding their partner (age, education, occupation, average income), and, if relevant, the partner's reasons for refusing to undergo HIV testing. Serological test results, gravidity, and number of antenatal care visits were extracted from their medical records. The protocol was conducted in the respect for the individual, the right to self-determination and the right to make informed decision regarding participation in the project, both initially and during the course of the research which in accordance with the principles of the Declaration of Helsinki.

We used STATA/SE version 10.0 to calculate/analyze the rate of HIV testing, baseline characteristics, and partners' reasons for refusing to undergo HIV testing in terms of mean, $\mathrm{SD}$, percentage, and 95\% confidence interval (CI) to demonstrate the precision of the data. We then explored the factors related to male partners refusing to undergo HIV testing in terms of crude odds ratio and used multivariate analysis to adjust the crude odds ratio at a 95\% confidence level.

\section{Results}

A total of 400 pregnant women were recruited to participate in this study between February and August 2018. On average, the women were younger than their partners. In terms of education, the majority of participants had at least a vocational certificate. One-third of the women were unemployed, whereas less than $5 \%$ of their male partners were unemployed. The women had a lower average income than their partners, but $>60 \%$ of the participants in both groups made $\geq 300$ baht/day, as demonstrated in Table 1 . Serological tests for syphilis were reactive for 3 patients, and those for hepatitis were positive for 2 , all of whom were women.

Over $90 \%$ of couples were living together, though more than half had no official marriage certificate, as shown in Table 2. The mean relationship duration was $5.3 \pm 4.9$ years. Almost half of the women were experiencing their first pregnancy. A substantial portion (15\%) of
Table I Baseline Characteristics of the Studied Couples

\begin{tabular}{|c|c|c|}
\hline Baseline Characteristics & $\begin{array}{l}\text { Pregnant } \\
\text { Women } \\
\mathbf{N}=\mathbf{4 0 0}\end{array}$ & $\begin{array}{l}\text { Partners } \\
N=400\end{array}$ \\
\hline Age (mean, SD) & 28 years (SD 5.52) & 31.58 (SD 7.34) \\
\hline $\begin{array}{l}\text { Education } \\
\text { Primary school } \\
\text { Secondary school } \\
\text { Vocational certificate } \\
\text { Undergraduate or graduate }\end{array}$ & $\begin{array}{l}5(1.3 \%) \\
149(37.3 \%) \\
90(22.5 \%) \\
156(39.0 \%)\end{array}$ & $\begin{array}{l}21(5.3 \%) \\
125(31.3 \%) \\
129(32.3 \%) \\
125(31.3 \%)\end{array}$ \\
\hline $\begin{array}{l}\text { Occupation } \\
\text { Unemployed } \\
\text { Government official } \\
\text { Officer } \\
\text { Private business } \\
\text { Farmer } \\
\text { Temporary employee }\end{array}$ & $\begin{array}{l}109(27.4 \%) \\
34(8.6 \%) \\
148(37.3 \%) \\
76(19.1 \%) \\
5(1.3 \%) \\
24(6.1 \%)\end{array}$ & $\begin{array}{l}17(4.4 \%) \\
68(17.4 \%) \\
168(43.1 \%) \\
84(21.5 \%) \\
13(3.3 \%) \\
40(10.3 \%)\end{array}$ \\
\hline $\begin{array}{l}\text { Average income (per month; } \\
\text { median [P25-75th percentile]) }\end{array}$ & $\begin{array}{l}13,000 \text { baht } \\
{[0-20,000]}\end{array}$ & $\begin{array}{l}15,000 \text { baht } \\
{[11,500-23,000]}\end{array}$ \\
\hline $\begin{array}{l}\text { Average Income (per day) } \\
\quad<300 \text { baht/day } \\
\geq 300 \text { baht/day }\end{array}$ & $\begin{array}{l}128(32.2 \%) \\
270(67.8 \%)\end{array}$ & $\begin{array}{l}128(32.2 \%) \\
270(67.8 \%)\end{array}$ \\
\hline $\begin{array}{l}\text { Reactive/positive serology } \\
\text { testing result } \\
\text { VDRL } \\
\text { HBV }\end{array}$ & $\begin{array}{l}(\mathrm{N}=400) \\
3(0.8 \%) \\
2(0.5 \%)\end{array}$ & $\begin{array}{l}(\mathrm{N}=150) \\
0 \\
0\end{array}$ \\
\hline
\end{tabular}

Abbreviations: VDRL, Venereal Disease Research Laboratory; HBV, Hepatitis B Virus.

the pregnancies was unplanned, and $38.3 \%$ of the participants used no contraception before the current pregnancy. The mean gestational age at first visit to the ANC unit was $10 \pm 5.2$ weeks.

Of the 400 women recruited, only 150 had male partners who agreed to undergo HIV testing. Among the couples in which one or both members were found to be positive for HIV, there was 1 seroconcordant couple, 1 serodiscordant couple in which the woman was found to be positive, and 3 serodiscordant couples in which the male partner was positive, as shown in Table 3 .

Two hundred fifty of the male partners refused to undergo HIV testing. According to the women, the most common reason was that their partners had already been tested once before, as shown in Table 4. Many of the women said that their partners did not think they were at risk, that they had recently been tested before the current pregnancy, or that they could not take time off from work.

Factors in which might affect the partner to take the test were analysed as crude OR, and all these factors were 
Table 2 Baseline Characteristics of the Current Pregnancy Status

\begin{tabular}{|c|c|}
\hline Baseline Characteristics & $\begin{array}{l}\text { Pregnant Women } \\
(\mathrm{N}=400)\end{array}$ \\
\hline $\begin{array}{l}\text { Marital status } \\
\text { Certificated and cohabitating } \\
\text { Certificated but separated } \\
\text { Not certificated cohabitating } \\
\text { Not certificated and separated }\end{array}$ & $\begin{array}{l}164(41 \%) \\
11(2.8 \%) \\
210(52.5 \%) \\
15(3.8 \%)\end{array}$ \\
\hline $\begin{array}{l}\text { Duration of relationship (yrs. mean } \pm S D \text { ) } \\
\text { History of sexually transmitted infection }\end{array}$ & $\begin{array}{l}5.3 \pm 4.9 \\
28(7.1 \%)\end{array}$ \\
\hline $\begin{array}{l}\text { Contraceptive use before the current } \\
\text { pregnancy } \\
\text { No contraception } \\
\text { Condom } \\
\text { Intrauterine device } \\
\text { Contraceptive pills } \\
\text { Injection } \\
\text { Implant } \\
\text { Others } \\
\text { Sterilization } \\
\text { Emergency pills } \\
\text { Contraceptive patch }\end{array}$ & $\begin{array}{l}\text { I5 (38.3\%) } \\
2 \mid(5.3 \%) \\
4(1.0 \%) \\
190(47.5 \%) \\
35(8.8 \%) \\
5(1.3 \%) \\
5(1.3 \%) \\
2(0.5 \%) \\
2(0.5 \%) \\
I(0.3 \%)\end{array}$ \\
\hline $\begin{array}{l}\text { Primi-gravidity } \\
\text { Unplanned pregnancy } \\
\text { GA at first visit ANC (mean } \pm S D)\end{array}$ & $\begin{array}{l}180(45 \%) \\
60(15 \%) \\
10.2 \pm 5.2\end{array}$ \\
\hline
\end{tabular}

Abbreviations: GA, gestational age; ANC, antenatal care.

Table 3 Couples HIV Testing and HIV Infection Rates

\begin{tabular}{|l|l|l|}
\hline Rate of Testing & Couple(s) (\%) & $\mathbf{9 5 \%} \mathbf{~ C l}$ \\
\hline Couples screening & $150(37.5)$ & $32.82,42.55$ \\
Anti-HIV positive in women & $2(1.3)$ & $0.16,4.73$ \\
Anti-HIV positive in men & $4(2.7)$ & $0.74,6.78$ \\
\hline Discordant infection & $4(2.70$ & $0.74,6.78$ \\
I. +ve women and -ve men & $\mathrm{I}(0.7)$ & $0.02,3.7 \mathrm{I}$ \\
2. - ve women and +ve men & $3(2.0)$ & $0.42,5.8 \mathrm{I}$ \\
\hline
\end{tabular}

considered to analyse for adjusted OR. Factors including teenage pregnancy, socioeconomic status, level of education, marital status, timing of antenatal care, history of sexually transmitted infection, and gravidity were not significant as to whether or not the male partners were willing to undergo HIV testing. The only significant factor was the woman having had other partners in the past, as shown in Table 5.

\section{Discussion}

In this cross-sectional study, the rate of couples undergoing HIV testing at the Srinagarind Hospital ANC unit was 37.5\%
Table 4 Partners' Reasons for Refusing to Undergo HIV Testing

\begin{tabular}{|l|l|}
\hline $\begin{array}{l}\text { Partners' Reasons for Refusing to Undergo HIV } \\
\text { Testing }\end{array}$ & $\mathbf{N}=\mathbf{2 5 0}$ (\%) \\
\hline $\begin{array}{l}\text { He already knew his HIV status. } \\
\text { He had recently undergone HIV testing before her } \\
\text { current pregnancy. }\end{array}$ & $94(37.6 \%)$ \\
He could not take time off from work. & $42(17.6 \%)$ \\
He thought that neither he nor his partner was at risk for & $37(14.8 \%)$ \\
HIV infection. & $10(4 \%)$ \\
He worked or stayed far away (other provinces or \\
abroad) & $9(3.6 \%)$ \\
He was afraid of needles. & $8(3.2 \%)$ \\
He thought that the testing was not necessary. & $3(1.2 \%)$ \\
He planned to undergo HIV testing at his local hospital. & $3(1.2 \%)$ \\
\hline Divorce & \\
\hline
\end{tabular}

(150 out of 400 couples). The rate found in this study was higher than in one conducted in Lemo District in Ethiopia, which found that only $30.9 \%$ (123/401) of accompanying partners were tested and 29.18\% (117/401) underwent counseling at the ANC/PMTCT unit. ${ }^{14}$ Another study in the Dominican Republic, Georgia, and India also found low rates of couples undergoing HIV counseling and testing (9.1\% in the Dominican Republic, $13.8 \%$ in Georgia and $36.8 \%$ in India). ${ }^{15}$ By contrast, a 2015 Thailand AIDs response progress report found that the percentage of couples who underwent HIV testing at the ANC unit had increased to $41 \%$ in 2014. However, this is still far below the 2016 target of $60 \%{ }^{3}$ One study conducted in Eastern Uganda attempted to improve the rate of male partners undergoing HIV testing by implementing routine (as opposed to voluntary) counseling and testing as part of antenatal care services. Nonetheless, the overall number of male partners who were tested for HIV remained low. ${ }^{16}$ In our study, we attempted to improve participants' understanding the importance of HIV testing and counseling the pregnant women with more intensively of the information sheet to let them have more rounds of thought together with her partners, according to the suggestions laid out in the Thailand AIDs response progress report mentioned above. ${ }^{3}$ However, the rate of male partners who underwent HIV testing and counseling was still low. This finding was consistent with those of a previous study conducted in eastern Uganda, in which the results in an intervention group were similar to those in the control group. ${ }^{17}$ A study conducted in Sub-Saharan Africa found that issuing invitation letters also had no effect on HIV testing rates in partners, but that enhanced psychosocial interventions and complex community interventions increased male partner 
Table 5 The Factors Associated with Couples Refusing to Undergo HIV Testing

\begin{tabular}{|c|c|c|c|c|}
\hline Risk Factors & OR & $95 \% \mathrm{Cl}$ & Adjusted OR & $95 \% \mathrm{Cl}$ \\
\hline Teenage pregnancy (Maternal age $<20$ yrs.) & 1.06 & $0.40-2.99$ & 0.82 & $0.27,2.53$ \\
\hline Low socioeconomic status (daily income $<300$ baht) & 2.05 & $0.52-11.76$ & 2.64 & $0.53,13.15$ \\
\hline \multicolumn{5}{|l|}{ Undergraduate education } \\
\hline Participants & 0.88 & $0.57-1.37$ & 0.74 & $0.44,1.23$ \\
\hline Partners & 1.15 & $0.73-1.82$ & 1.32 & $0.77,2.25$ \\
\hline Unstable marital status & 0.99 & $0.64-1.52$ & 0.91 & $0.59,1.43$ \\
\hline Late ANC First visit ANC $>20$ wks.) & 0.91 & $1.33-2.63$ & 0.75 & $0.28,2.00$ \\
\hline History of STD infection & 0.61 & $0.01-47.92$ & 0.84 & $0.05,13.78$ \\
\hline She had had another partner in the past. & $1.78^{*}$ & $1.13-2.84$ & $1.75^{*}$ & I.10, 2.77 \\
\hline Multi-gravidity & 1.38 & $0.89-2.10$ & 1.42 & $0.93,2.17$ \\
\hline
\end{tabular}

Note: ${ }^{*}$-value $<0.05$.

Abbreviation: STD, sexually transmitted infection.

involvement and the uptake of PMTCT services to a greater extent than any other intervention. ${ }^{18}$ Another related study in Uganda also suggested that future work should consider multi-level approaches to partner testing, focusing not only on interpersonal factors, but also on structural and healthsystem level factors ${ }^{19}$ such as home-based voluntary counseling and testing (VCT; 20), routine HIV counseling and testing, ${ }^{18,20}$ and self-test kits ${ }^{21}$ in order to increase male partners' involvement in HIV testing. Another cause of the low rate of male partner HIV testing in our study might be that government hospitals in Thailand allow free HIV testing twice per year. It is possible that large number of the male partners in our study already knew their HIV status. This is supported by the fact that the most common reason reported for the male partner refusing to take an HIV test.

This study found that neither teenage pregnancy, socioeconomic status, education levels, stability of marital status, nor timing antenatal care affected the willingness of male partners to undergo HIV testing. The only significant factor was the woman having had other partners in the past (Table 5). One explanation for this comes from a report from Uganda in which having multiple partners was found to be a barrier to engagement in couples-based services because of the risk of positive results that made their spouses threatening. ${ }^{22,23}$

There have been studies conducted in Africa that have shown usually high rates of positive HIV test results in countries such as Nigeria $\left(2.1 \%\right.$ in females $\left.{ }^{24}\right)$ and Mozambique ( $5 \%$ in males, $18 \%$ in females $\left.{ }^{25}\right)$. While the studies in Thailand have found the rates have been $0.5 \%$ in the period between $1999-2008$ and $0.4 \%$ in $2009-2010$, these were concordant infection. ${ }^{26}$ In this study, the positive rate in the men was twice as high as that in the women $(2.6 \%$ vs $1.3 \%)$, and the discordant infection rate was higher than expected at $2.6 \%$ (Table 3). These findings compared with those of other studies imply that the HIV transmission rate among couples is increasing, despite the Thailand National AIDs Strategic plan to achieve the goal of eradicating AIDs by $2030 .{ }^{3}$ While many ANC clinics usually offer HIV testing to the pregnant women only and ask to test her partners only when she had a positive test. In this context, the vertical transmission could not reduce especially when the couples had sero-discordant. The high discordant infection rate among positive couples and the higher positive rate in men than in women suggests that routine couples counseling and testing should be considered in order to achieve the goal of the vertical transmission of HIV to be less than $1 \%$. This modality might also have the potential to substantially reduce the number of new HIV infections since the one with positive test will be supported to take the medication to reduce viral load which would reduce the transmission rate when contact with other negative one.

The higher positive test in men than in women implies that strategies should be considered in order to increase male involvement in HIV testing in each aspect as it could possibly be a major source of vertical transmission. The first strategy we would propose is that the community healthcare policies should include clear steps promoting routine HIV counseling and testing as part of ANC services. Second, multi-level interventions should be implemented to promote male HIV testing. These could include personal communication regarding the benefits of testing such as the distribution of official invitation letters that explain the necessity of prophylactic antiretroviral agents for the infants of women whose partners are highly suspected of HIV infection and who 
refuse to undergo HIV testing without justifiable reasons. Third, routine or enforced (as opposed to voluntary) HIV counseling and testing should be implemented for the male partners of pregnant women after all intensive modalities to have voluntarily testing does not work, but this method should be careful for ethical problem. In addition, knowledge regarding HIV infection and appropriate attitudes toward HIV testing should be promoted through the media and educational campaigns.

This study attempted to increase the rate of couple HIV testing through the provision of brochures/information sheets for patients to take home and read before deciding whether or not to undergo HIV testing. This was to assure that the women had enough time to consider the importance of HIV testing and attempt to convince their partners to take the test. The fact that this study found a low rate of couple HIV testing despite these efforts further emphasizes these findings. However, this study was conducted in only one tertiary care hospital, and results may vary by setting, possibly limiting its generalizability. Additionally, we interviewed only the pregnant women and did not have access to their partners if they did not accompany the women during ANC and refused to take the test. Therefore, these findings may reflect only the women's opinions regarding their partners not undergoing HIV testing.

\section{Conclusions}

We found a low rate of couples undergoing HIV testing and a substantial portion of discordant infection among positive couples. Therefore, couple testing should be encouraged to implement to reduce vertical transmission and number of new cases of HIV infection.

\section{Acknowledgment}

This study was financially supported by a Khon Kaen University Faculty of Medicine Invitation Research Grant.

\section{Disclosure}

The authors report no conflicts of interest in this work.

\section{References}

1. UNAIDS. Report on the Global AIDS Epidemic 2018. Geneva, Switzerland: UNAIDS; 2018.

2. Department of disease control. Thailand National Guidelines on HIV/ AIDS Treatment and Prevention 2017.1sted: The Agricultural CoOperative Federation of Thailand. LTD Publishing; 2017.

3. Thailand AIDS response progress report 2015. Reporting period: 2012-2014. Available from: http://aidsdatahub.org/dmdocuments/ UNGASS_2015_Thailand_Narrative_Report.pdf. Accessed November 28, 2014.
4. Tunthanathip P, Lolekha R, Bollen LJ, et al. Indicators for sexual HIV transmission risk among people in Thailand attending HIV care: the importance of positive prevention. Sex Transm Infect. 2009;85 (1):36-41. doi:10.1136/sti.2008.032532

5. Thailand AIDS response progress report 2012. Reporting period: 2010-2011. Available from http://aidsdatahub.org/dmdocuments/ UNGASS_2012_Thailand_Narrative_Report.pdf. Accessed February $5,2013$.

6. Roongpisuthipong A, Siriwasin W, Simonds RJ, et al. HIV seroconversion during pregnancy and risk for mother-to-infant transmission. J Acquir Immune Defic Syndr. 2001;26(4):348-351. doi:10.1097/ 00042560-200104010-00011

7. World health organization. Guidance on Couples HIV Testing and Counselling Including Antiretroviral Therapy for Treatment and Prevention in Serodiscordant Couples: Recommendations for a Public Health Approach. Geneva: World Health Organization; 2012. Available from: http://www.who.int/hiv/pub/guidelines/ 9789241501972/en/. Accessed December 31, 2014.

8. World Health Organization. Consolidated Guidelines on the Use of Antiretroviral Drugs for Treating and Preventing HIV Infection: Recommendation for a Public Health Approach. Geneva: World Health Organization; 2013.

9. The Voluntary HIV-1 Counseling and Testing Efficacy Study Group. Efficacy of voluntary HIV-1 counselling and testing in individuals and couples in Kenya, Tanzania, and Trinidad: a randomised trial. Lancet. 2000;356(9224):103-112. doi:10.1016/S0140-6736(00) 02446-6

10. Grinstead OA, Gregorich SE, Choi KH, Coates T. Positive and negative life events after counselling and testing: the voluntary HIV-1 counselling and testing efficacy study. Aids. 2001;15 (8):1045-1052. doi:10.1097/00002030-200105250-00013

11. Perinatal HIV Intervention Monitoring System report (Jan-Dec 2013). Bureau of Health Promotion. Thailand: Department of Health, Ministry of Public Health. Available from: http://pmtct.ana mai.moph.go.th/PHIMS/Report/RPT00_20150102144056044.pdf. Accessed March 7, 2014.

12. Orne-Gliemann J, Tchendjou PT, Miric M, du Lou AD, Dabis F Couple-oriented prenatal HIV counseling for HIV primary prevention: an acceptability study. BMC Public Health. 2010;10:197. doi:10.1186/1471-2458-10-197

13. Thailand Department of Health and UNFPA. A manual for operation and service protocol on men involvement to prevent HIV and promote maternal/child health 2009 (in Thai). Available from: http://rh. anamai.moph.go.th/all_file/brochure/Material\%20for\%20Provider/ MPM_OP_SOC.pdf. Accessed January 2, 2014.

14. Degefa Tadele B, Abera Beyamo M, Bayu B. Male partners involvement in prevention of mother-to-child transmission of HIV services in Southern Central Ethiopia: in case of Lemo District, Hadiya Zone. AIDS Res Treat. 2017;2017:Article ID 8617540, 8. doi:10.1155/2017/ 8617540

15. Tiendrebeogo T, Plazy M, Darak S, et al. Couples HIV counselling and couple relationships in India, Georgia and the Dominican Republic. BMC Public Health. 2017;17:901. doi:10.1186/s12889017-4901-8

16. Byamugisha R, Tylleskär T, Kagawa MN, Onyango S, Karamagi CA, Tumwine JK. Dramatic and sustained increase in HIV-testing rates among antenatal attendees in Eastern Uganda after a policy change from voluntary counselling and testing to routine counselling and testing for HIV: a retrospective analysis of hospital records, 2002-2009. BMC Health Serv Res. 2010;10:290. doi:10.1186/14726963-10-290

17. Byamugisha R, Åstrøm AN, Ndeezi G, Karamagi CA, Tylleskär T, Tumwine JK. Male partner antenatal attendance and HIV testing in eastern Uganda: a randomized facility-based intervention trial. J Int AIDS Soc. 2011;14:43. doi:10.1186/1758-2652-14-43 
18. Takah NF, Kennedy ITR, Johnman C. The impact of approaches in improving male partner involvement in the prevention of mother-tochild transmission of HIV on the uptake of maternal antiretroviral therapy among HIV-seropositive pregnant women in sub-Saharan Africa: a systematic review and meta-analysis. BMJ Open. 2017;7 (11):e018207. doi:10.1136/bmjopen-2017-018207

19. Kiene SM, Gbenro O, Sileo KM, Lule H, Wanyenze RK. How do we get partners to test for HIV?: predictors of uptake of partner HIV testing following individual outpatient provider initiated HIV testing in rural Uganda. AIDS Behav. 2017;21(8):2497-2508. doi:10.1007/s10461-0171817-3

20. Rujumba J, Neema S, Byamugisha R, Tylleskär T, Tumwine JK, Heggenhougen HK. Telling my husband, I have HIV is too heavy to come out of my mouth: pregnant women's disclosure experiences and support needs following antenatal HIV testing in eastern Uganda. J Int AIDS Soc. 2012;15(2):17429. doi:10.7448/IAS.15.2.17429

21. Choko AT, Kumwenda MK, Johnson CC, et al. Acceptability of woman-delivered HIV self-testing to the male partner, and additional interventions: a qualitative study of antenatal care participants in Malawi. J Int AIDS Soc. 2017;20(1):21610. doi:10.7448/IAS.20.1.21610

22. Sileo KM, Wanyenze RK, Lule H, Kiene SM. That would be good but most men are afraid of coming to the clinic: men and women's perspectives on strategies to increase male involvement in women's reproductive health services in rural Uganda. J Health Psychol. 2016;22(12):1552-1562. doi:10.1177/1359105316630297
23. Larsson EC, Thorson A, Nsabagasani X, Namusoko S, Popenoe R, Ekström AM. Mistrust in marriage-reasons why men do not accept couple HIV testing during antenatal care-a qualitative study in eastern Uganda. BMC Public Health. 2010;10:769. doi:10.1186/14712548-10-769

24. Akinleye O, Dura G, de Wagt A, Davies A, Chamla D. Integration of HIV testing into maternal, newborn, and child health weeks for improved case finding and linkage to prevention of mother-to-child transmission services in Benue State, Nigeria. Front Public Health. 2017;5:71. doi:10.3389/fpubh.2017.00071

25. Audet CM, Blevins M, Chire YM, et al. Engagement of men in antenatal care services: increased HIV testing and treatment uptake in a community participatory action program in Mozambique. AIDS Behav. 2016;20(9):2090-2100. doi:10.1007/s10461-016-1341-x

26. Lolekha R, Kullerk N, Wolfe MI, et al. Assessment of a couples HIV counseling and testing program for pregnant women and their partners in antenatal care (ANC) in 7 provinces, Thailand. BMC Int Health Hum Rights. 2014;14:39. doi:10.1186/s12914014-0039-2

\section{Publish your work in this journal}

HIV/AIDS - Research and Palliative Care is an international, peerreviewed open-access journal focusing on advances in research in HIV, its clinical progression and management options including antiviral treatment, palliative care and public healthcare policies to control viral spread. The manuscript management system is completely online and includes a very quick and fair peer-review system, which is all easy to use. Visit http://www.dovepress.com/testimonials.php to read real quotes from published authors. 